\title{
Quantitative Studies on the Rate of Cell Production in the Thymolymphatic Organs
}

\author{
II. Estimation of the Daily Mitotic Activity in \\ Young Adult Albino Rats*
}

By

\section{Hirohiko Ito}

Department of Anatomy, Yamaguchi Medical School, Ube

(Director: Prof. Bunsuke Osogoe)

In the preceding paper of this series a simple method for determination of the mitotic index in suspension of cell nuclei, which had been prepared from the thymolymphatic organs, was described. The present work is an attempt to estimate the daily rate of mitotic activity in the thymolymphatic system of young adult albino rats by this method and by using the drug, colchicine, which, in proper dosage, arrests dividing cells at metaphase. Its final aim is to make possible a calculation of the total number of cells newly produced by mitosis per day in the thymolymphatic organs, using the results of estimation of total cellular numbers in these organs by means of DNA determination ( $M$ o $n$ d e $n, 1959$ a).

\section{Material and Methods}

Male albino rats of a subline of the $\mathrm{W}$ is t a $\mathrm{r}$ strain, weighing approximately $200 \mathrm{~g}$, were chosen as the standard animals to be examined, as in the earlier studies (M o n d e n, 1955; $1959 \mathrm{a}, \mathrm{b}$; and

\footnotetext{
* Supported in part by a grant to Professor Bunsuke Osogoe from the Ministry of Education (Grant-in-Aid for Fundamental Scientific Research, Cooperative). A preliminary report covering certain phases of this study has been published (O s o g o e et al., 1957 and $O$ s o g o e and $A$ w a y a, 1958) and preliminary data were discussed at the conference on "Dynamics of Proliferating Tissues" held at Brookhaven National Laboratory, Upton, New York, September 5-8, 1956. (The Developmental Biology Conference Series, 1956. Edited by D. Price. Chicago: Univ. of Chicago Press, 1958.)
} 
I t o, 1959). They were fed on a standard laboratory diet, which consisted chiefly of unpolished rice, pressed barley and dried small sardine with a small amount of cod liver oil and minerals, supplemented once a week with cabbage or other vegetables.

The animals were divided into three groups. The first group consisted of 21 rats which served as controls. The second group, consisting of 27 rats, was used for a preliminary experiment to test the possibility of assessing the mitotic activity over a period of 2 to 8 hours after injection of colchicine. In the third group, which also comprised 27 rats, an attempt was made to assess the daily rate of mitosis, according to the technique of $\mathrm{Bertalanffy}$ and Leblond (1953), as will be mentioned below. All rats had been starved since the previous evening.

The animals of the first group were further divided into three subgroups (Controls I-III). Control I consisted of 7 normal untreated rats, Control II 5 adrenalectomized rats which were examined immediately after operation, and Control III 9 adrenalectomized rats which were examined 4-8 hours after operation (cf. Table 1). The animals of Controls I and II were killed at about 10:00 a.m. and those of Control III between 2:00 p. m. and 6:00 p. m. Each rat of the second group was given a subcutaneous injection of $0.10 \mathrm{mg}$ of colchicine per $100 \mathrm{~g}$ of body weight at 10:00 a.m. The animals of this group were killed at successive intervals from 2 to 8 hours after injection (cf. Table 2). The rats of the third group were further divided into 4 subgroups consisting of 7 animals each. Each rat was also given a subcutaneous injection of colchicine in the same dosage as in the second group. The rats of the first subgroup received the injection at 10:00 a. m., those of the second at $4: 00 \mathrm{p} . \mathrm{m}$., those of the third at $10: 00 \mathrm{p} . \mathrm{m}$. on the same day, and finally those of the fourth subgroup at 4:00 a.m. on the next day. All animals were killed 6 hours after injection (cf. Table 3). In this way the same experiment was repeated over 4 successive 6 -hour periods, thus covering a total of 24 hours. This method was adopted because some diurnal variations were to be seen in the mitotic activity in the thymolymphatic organs.

Immediately after the animals had been killed by cervical dislocation and bleeding, the thymolymphatic organs to be examined (the thymus, mesenteric lymph nodes and other lymph nodes*) were

* The spleen and Peyer's patches were not included in the present study. 
removed and weighed. The greater part of each of the excised organs was used for mitotic counts in suspension of nuclei and the remaining small portion for histological examination after fixing in $\mathrm{Z}$ e n k e r-formol.

The methods used for preparation of suspensions of nuclei from the thymolymphatic organs and for mitotic counts in this suspension have been described in detail in the preceding paper (I t o, 1959). Since colchicine produces the typical phenomena of acute stress, i. e., extensive destruction of proliferating lymphocytes in the lymphatic nodules and other parts of the lymphoid tissues, the adrenal glands of the animals had been removed immediately before colchicine injection. Adrenalectomy was also performed on 14 aminals of the control group (Controls II-III), with the aim to disclose the effect of the adrenalectomy itself on the mitotic activity in the thymolymphatic organs.

\section{Results}

The results of mitotic counts on 7 normal untreated rats (Control I) are given in Table 1, together with those on 5 rats immediately after adrenalectomy and with those on 9 rats from 4 to 8 hours after adrenalectomy. All figures in the table are expressed in percentage of the total nucleated cells counted. Normal values of the mitotic index in young adult albino rats were found to be $1.13 \pm$ $0.06 \%$ in the thymus, $0.79 \pm 0.06 \%$ in the mesenteric lymph node, and $0.75 \pm 0.06 \%$ in the other lymph nodes. It should be noticed here that the values of the mitotic index were much greater in the thymus than in the lymph nodes.

As regards the effect of the adrenalectomy itself on the mitotic activity in the thymolymphatic organs, a considerable reduction in the values of the mitotic index was observed from 4 to 8 hours after operation. This must be taken into consideration in the discussion of the results to be presented below.

After injection of colchicine in a dose of $0.10 \mathrm{mg}$ per $100 \mathrm{~g}$ of body weight into adrenalectomized rats immediately after operation, there was an almost linear increase in the percentage of mitoses in the thymus, mesenteric lymph nodes and other lymph nodes until the 8th hour (cf. Fig. 1 and Table 2). It is important to emphasize here that the rate of increase in the number of mitoses after colchicine injection was much greater in the thymus than in the lymph 


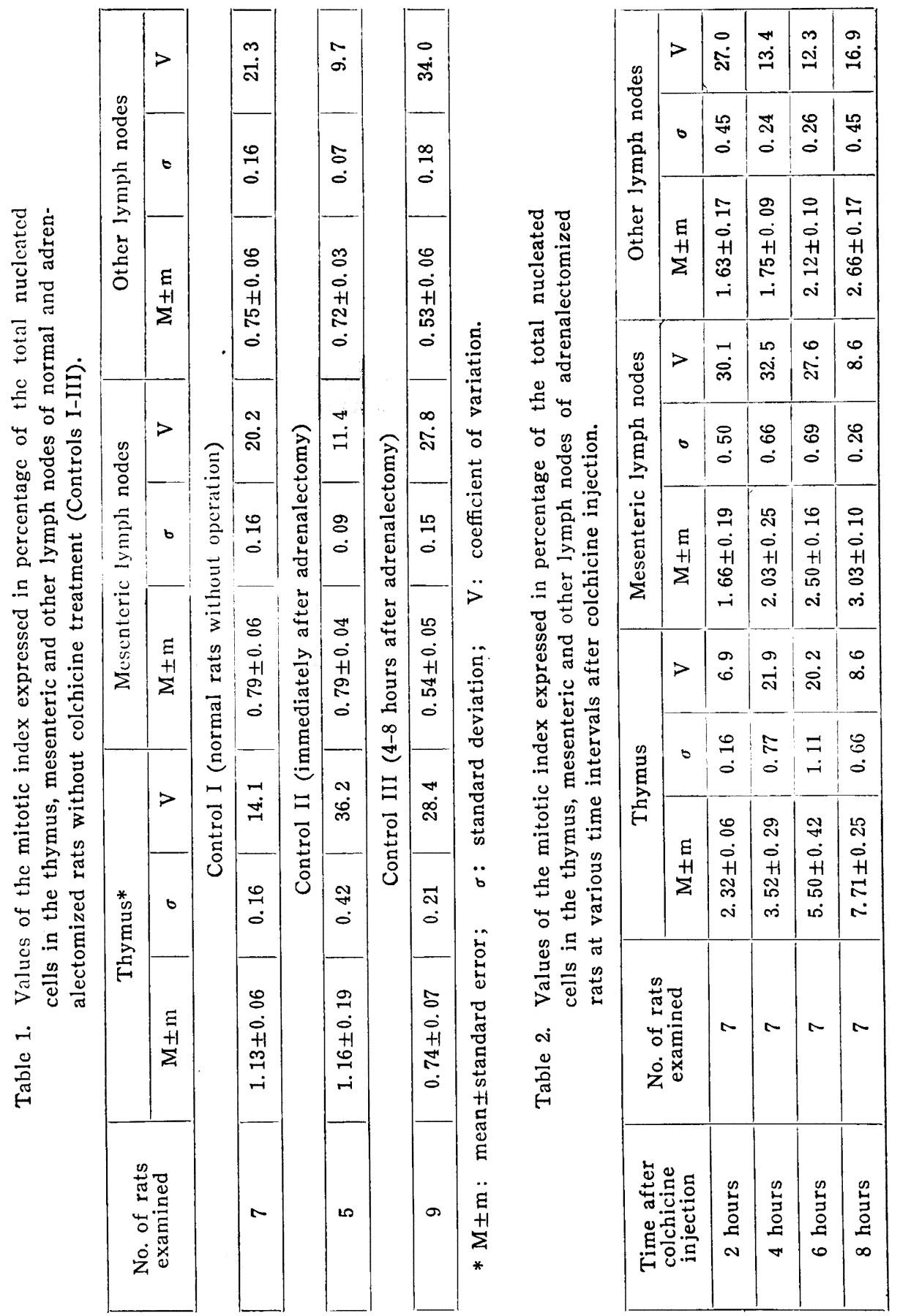




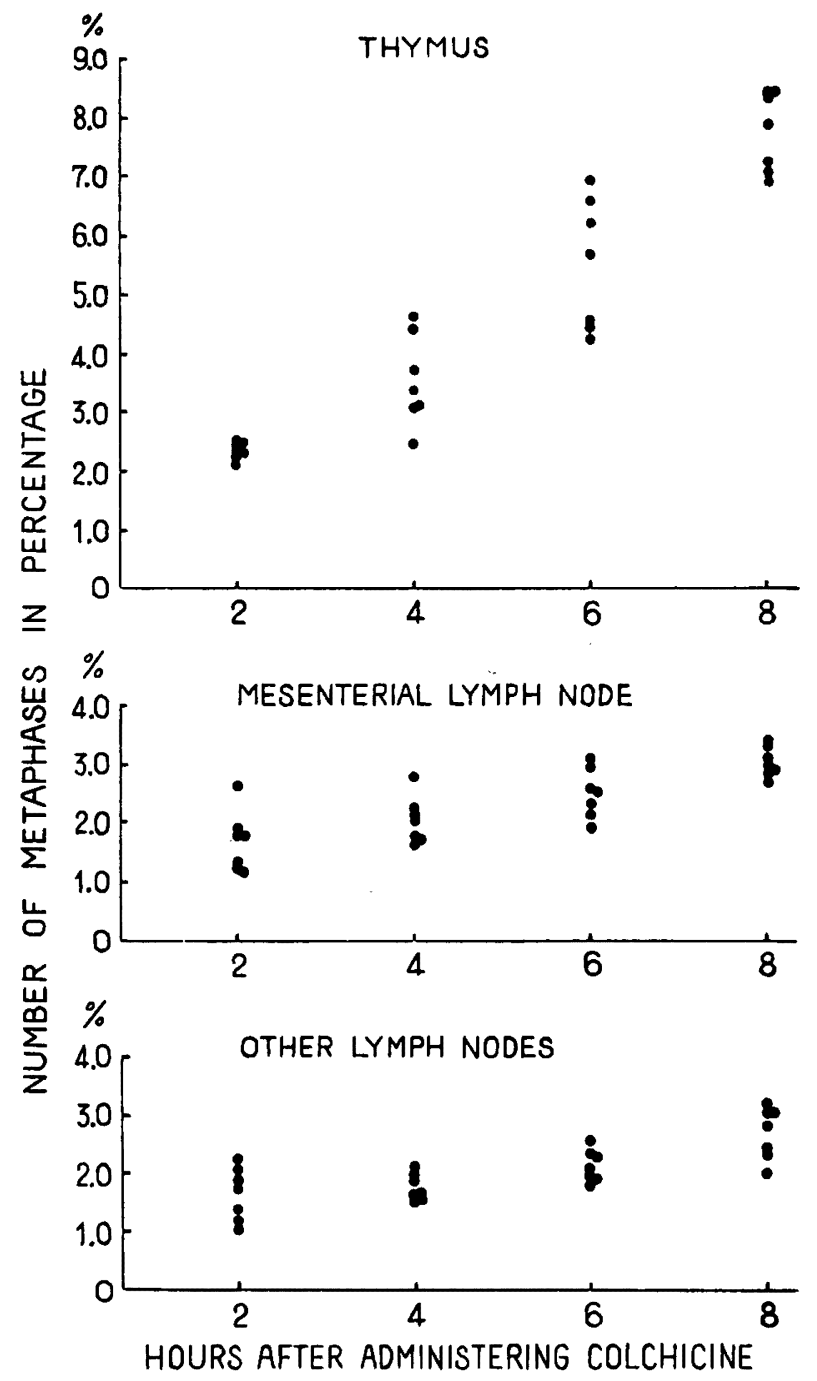

Fig. 1. Number of arrested metaphases (expressed in percentage of the total nucleated cells counted) in the thymus, mesenteric lymph nodes and other lymph nodes at various time intervals after colchicine administration. Note that the number of metaphases continues to increase for 8 hours after injection.

nodes.

Since some diurnal variations were to be seen in the mitotic activity in the thymolymphatic organs, the total percentage of mitoses per day in each organ was computed by adding the mean values 


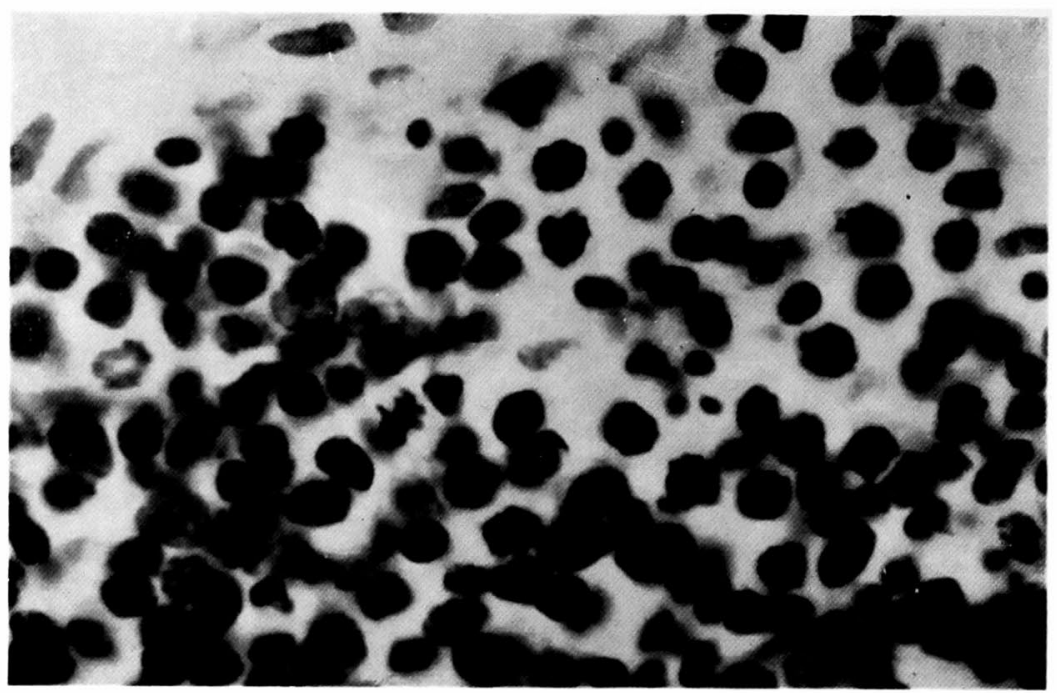

Fig. 2. Accumulation of numerous mitotic figures arrested at metaphase in the cortex of the thymus 8 hours after injection of colchicine. Many of the arrested metaphases are degeneration by nuclear pyknosis and $a$ few of them by nuclear fragmentation. $\times 1000$.

which were obtained at intervals of 6 hours from seven samples each, as shown in Table 3. The colchicine-treatment for a 6-hour period was adopted here because many of the metaphases arrested by colchicine began to degenerate by nuclear pyknosis and fragmentation from the 6 th or 8 th hour on (Fig. 2). In this way the daily mitotic rate in each organ was found to be $22.23 \pm 0.77 \%$ in the thymus, $7.85 \pm 0.37 \%$ in the mesenteric lymph nodes, and $6.65 \pm 0.26 \%$ in the other lymph nodes.

In regard to diurnal variations in the mitotic activity in the thymolymphatic organs, greater mitotic activity was observed during the period between 4:00 a. m. and 4:00 p. m. than between 4:00 p. m. and 4:00 a. m. (cf. Table 3). A similar finding that the day-rats showed more mitoses than the night-rats has been reported by $\mathrm{J}$ a f $\mathrm{e}$ (1954) in regenerating liver and by $\mathrm{M} u ̈ \mathrm{hl}$ e man $\mathrm{n}$ et al. (1956) in the oral epithelium and the thyroid.

\section{Discussion}

The present measurements have yielded generally much higher values of the mitotic index for the thymolymphatic tissues than the 
Rate of Cell Production in Thymolymphatic Organs II

\begin{tabular}{|c|c|c|c|}
\hline \multirow{11}{*}{ 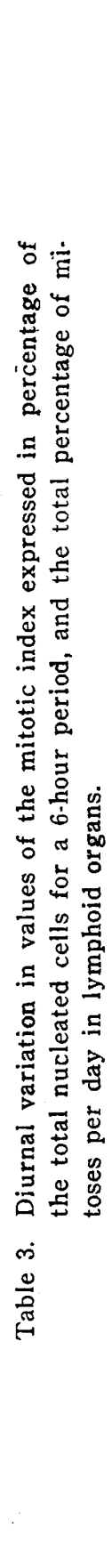 } & \multirow{3}{*}{ 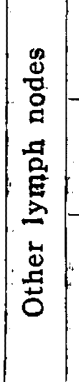 } & 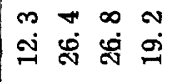 & 1 \\
\hline & & 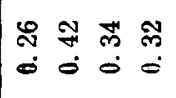 & 1 \\
\hline & & 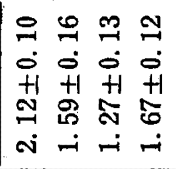 & $\begin{array}{l}2 \\
0 \\
+1 \\
+1 \\
0 \\
0 \\
0\end{array}$ \\
\hline & \multirow{3}{*}{ 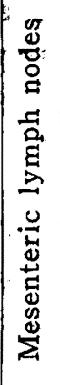 } & 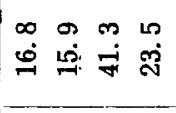 & 1 \\
\hline & & 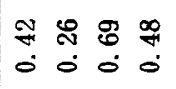 & 1 \\
\hline & & 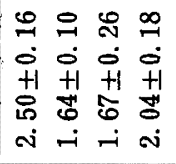 & $\begin{array}{l}\hat{m} \\
0 \\
+ \\
+1 \\
\infty \\
\infty\end{array}$ \\
\hline & \multirow{3}{*}{ 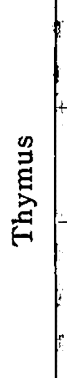 } & 穴 & 1 \\
\hline & & 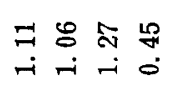 & 1 \\
\hline & & 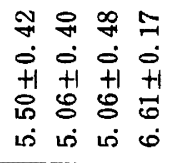 & 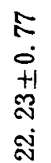 \\
\hline & 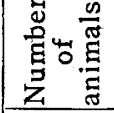 & $N \sim N$ & 1 \\
\hline & 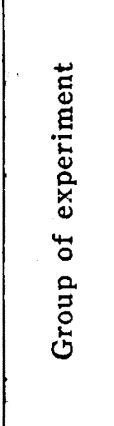 & 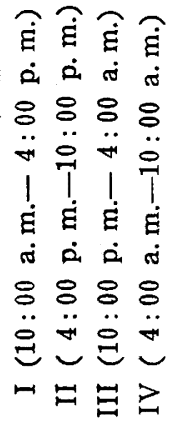 & 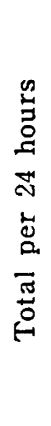 \\
\hline
\end{tabular}

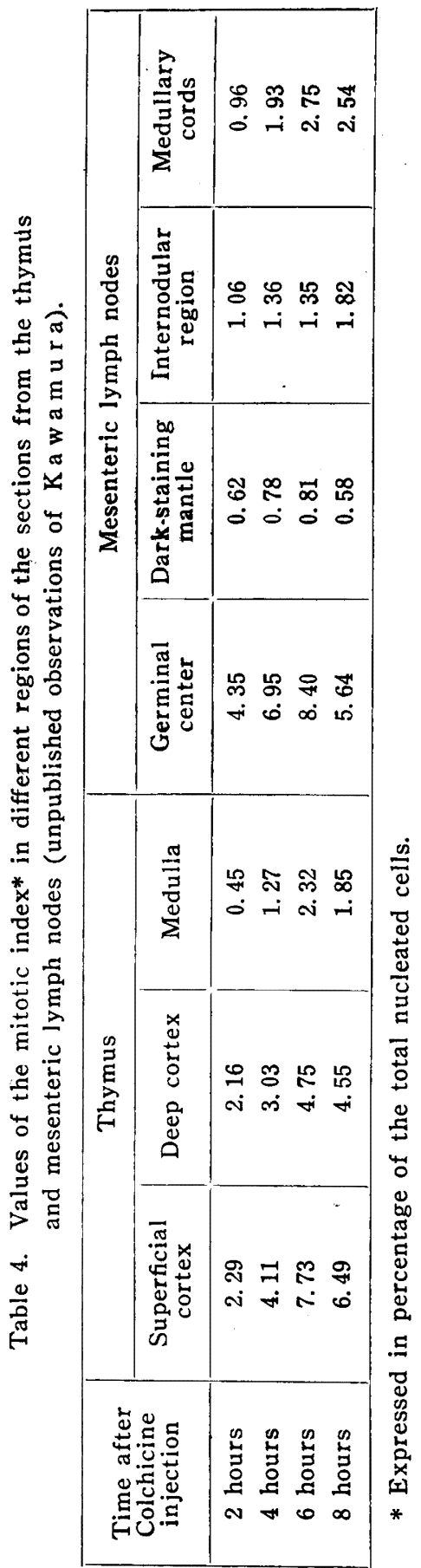


corresponding figures reported by $\mathrm{And} r$ e a s e $\mathrm{n}$ and $\mathrm{Ch} \mathrm{h}$ is te $\mathrm{nsen}$ (1949) who employed essentially the same methods as used in the present study. Their figures in young mature male rats were $0.216 \%$ in the thymus and $0.058 \%$ in the total lymph nodes; whereas our figures in male rats weighing around $200 \mathrm{~g}$ were $1.13 \%$ in the thymus, $0.79 \%$ in the mesenteric lymph nodes, and $0.65 \%$ in the other lymph nodes. Thus, our figures are about 5-13 times as great as those of Andreasen and Christensen. The reason for this discrepancy is not apparent. However, it is probable that strain differencies and variations in diet are partly responsible. In addition, it should be taken into account that the method for mitotic counts employed in the present study tended to yield higher values of the mitotic index than a similar method of $\mathrm{C} \mathrm{hr}$ iste $\mathrm{n}$ se $\mathrm{n}(1950)$, as has previously been emphasized by It o (1959).

Of particular interest in this connection are the values of the mitotic index determined in sections from the different regions of the thymus and mesenteric lymph nodes in young mature albino rats of the same strain as used in the present study. As shown in Table 4, the mitotic activity is unexpectedly high in certain regions of the thymolymphatic organs, notably in the germinal centers of the lymph node and in the cortex of the thymus. In his extensive quantitative studies on the thymolymphatic tissues of young adult albino rats on the basis of mitotic counts in tissue sections, $\mathrm{K}$ in $\mathrm{dred}$ $(1942,1955)$ also reported relatively high values comparable to our figures. From the above consideration it can be stated that the relative high values of the mitotic index obtained in the present study for the thymolymphatic tissues is not quite unreasonable.

Another point of interest is that in young mature albino rats the mitotic activity in the thymus was definitely greater than that in the lymph node. A similar finding has previously been reported by Kindred (1942, 1955), Andreasen and Ottesen (1945), and Andreasen and Christensen (1949). In view of the morphological and physiological identity of the thymocyte with the lymphocyte, these authors considered the thymus of the growing rat to be the most active lymphocytopoietic organ. The present author also agrees with this view and regards the thymus as being one of the most important seats of lymphocyte production.

The principal objective of the present study is to estimate the daily' rate of mitotic activity in the thymolymphatic organs by the 
colchicine method, using the results of estimation of total cellular numbers in these organs by means of DNA determination (Monden, 1959a). It was found that the daily mitotic rate was as great as $22.23 \pm 0.77 \%$ in the thymus, $7.85 \pm 0.37 \%$ in the mesenteric lymph nodes, and $6.65 \pm 0.26 \%$ in the other lymph nodes, as shown in Table 3. The figures for the total number of lymphocytes in the thymolymphatic organs of standard rats have been estimated by Monden $(1959 \mathrm{a})$ to be $(1,071 \pm 145) \times 10^{6}$ in the thymus, $(684 \pm 123) \times 10^{6}$ in the mesenteric lymph nodes, $(1,031 \pm 106) \times 10^{6}$ in the other lymph nodes, $(1,100 \pm 169) \times 10^{6}$ in the spleen, $(382 \pm 34) \times 10^{6}$ in the P e y e r's patches; and $(4,268 \pm 259) \times 10^{6}$ in the whole thymolymphatic organs. If we assume that the mitotic rate is the same for both the lymphocytic and the non-lymphocytic elements, and that the daily mitotic rate in the spleen and $\mathrm{Peyer}$ 's patches is equal to that in the lymph nodes other than the mesenteric lymph nodes, the number of lymphocyte mitoses per day in the thymolymphatic organs may easily be calculated. The figures obtained were as follows: $(238 \pm 33.3) \times 10^{6}$ in the thymus; $(54 \pm 9.9) \times 10^{6}$ in the mesenteric lymph nodes; $(69 \pm$ $7.5) \times 10^{6}$ in the other lymph nodes; $(73 \pm 11.5) \times 10^{6}$ in the spleen; $(26 \pm 1.8) \times 10^{6}$ in the $\mathrm{P}$ e y e r's patches; totaling $(459 \pm 37.4) \times 10^{6}$ in the whole thymolymphatic organs.

The number of lymphocytes needed for daily growth of the thymolymphatic organs was roughly estimated to total $26.6 \times 10^{6}$ in the whole lymphoid organs, assuming the rate of growth of the tissue to be $0.624 \%$ per day according to $\mathrm{K}$ in d red (1942). Subtracting this figure from the number of total lymphocyte mitoses per day in the whole thymolymphatic organs, the average number of excess mitoses of lymphocytes per day in the thymolymphatic system was found to be $432 \times 10^{6}$. This is 3.3 times as great as the number of lymphocytes present in the circulating blood. For this calculation an estimate of $(132 \pm 12.0) \times 10^{6}$ was used for the total number of lymphocytes present in the circulating blood (cf. M o n de n, 1959b).

The data on the daily mitotic rate in the thymolymphatic organs given in Table 3 allows a direct calculation of the turnover time of the lymphocytes in these organs. Here, the term "turnover time" denotes the time taken for the replacement of a number of cells equal to that in the whole population ( $\mathrm{Leblond}$ and $\mathrm{Walker}$, 1956). Since in the thymus the daily mitotic rate was estimated to be $22.23 \%$ on the average, the turnover time of the lymphocytes in 
this organ is then calculated to be 4.5 days, dividing 100 by 22.23. Likewise, the corresponding figures in lymph nodes are calculated to be 12.8 days in the mesenteric nodes and 15.0 days in the other nodes.

An indirect measurement of turnover time is also possible on the basis of the data obtained in the present study. If the duration time of mitosis or mitotic time (MT) and the mitotic index (MI) are known, the intermitotic time (IT) of tissue can be calculated from $\mathrm{H}$ of $\mathrm{f} \mathrm{m}$ a n's formula (H of $\mathrm{f} \mathrm{m}$ a $\mathrm{n}, 1947,1953$ ):

$$
\mathrm{IT}=\mathrm{MT} / \mathrm{MI} \text {. }
$$

Although, strictly speaking, the turnover time is the sum of the intermitotic time plus the mitotic time, the turnover time may be regarded as being approximately equal to the intermitotic time in the greater majority of tissue cells. This is valid because the mitotic time is usually a small fraction, of the order of a few percent at most, of the intermitotic time. Since, as shown in Table 1, normal values of the mitotic index in the thymolymphatic tissues are already known, only the mitotic time remains to be estimated for the calculation of turnover time.

The mitotic time may be estimated from the rate of accumulation of mitotic figures after injection of colchicine, using Dustin's formula* :

$$
\mathrm{A}=\mathrm{M} \cdot \mathrm{t}
$$

where A equals the calculated duration of mitosis, $M$ is the original mitotic index, and $X$ is the observed mitotic index after $t$ hours of exposure to colchicine. The figures obtained after exposure to colchicine for from 2 to 8 hours are given in Table 5 .

Table 5. Values of the mitotic time of dividing cells in the thymolymphatic organs estimated after exposure to colchicine for from 2 to 8 hours.

\begin{tabular}{|c|c|c|c|}
\hline $\begin{array}{c}\text { Time of exposure to } \\
\text { colchicine in hours }\end{array}$ & Thymus (hour) & $\begin{array}{c}\text { Mesenteric lymph } \\
\text { nodes (hour) }\end{array}$ & $\begin{array}{c}\text { Other lymph } \\
\text { nodes (hour) }\end{array}$ \\
\hline 2 & 0.97 & 0.95 & 0.92 \\
4 & 1.28 & 1.55 & 1.71 \\
6 & 1.23 & 1.89 & 2.14 \\
8 & 1.17 & 2.52 & 2.25 \\
\hline
\end{tabular}

* Cited from L u s hba u g (1@56). 
As seen from the table, the mitotic time varies from 0.92 to 2.52 hours in length. However, the figures estimated by the colchicine technique tend to be much greater than-often about twice as great as-those obtained by other methods (L u s h b a g h, 1956), probably due to the toxic action of the drug on cell division. It is generally conceded that the rate of entrance into mitosis is somewhat diminished by the colchicine and, in addition, that not all the mitosis are arrested at metaphase. In view of these facts the author assumed the average mitotic time of dividing cells in the thymolymphatic tissues to be about one hour. Besides, a mitotic cycle of 30 -minute duration was also considered possible. In his extensive quantitative study of the thymolymphatic organs of rats, $\mathrm{Kind} \mathrm{red} \mathrm{(1942)} \mathrm{also}$ assumed the mitotic time to be of either 1-hour or 30- minute duration.

Table 6. Values of the turnover time or intermitotic time of the lymphocytes in the thymolymphatic organs estimated by the direct and indirect methods.

\begin{tabular}{|c|c|c|c|}
\hline \multirow{2}{*}{ Crgan } & \multirow{2}{*}{$\begin{array}{l}\text { Direct method } \\
\text { (colchicine } \\
\text { method) }\end{array}$} & \multicolumn{2}{|c|}{ Indirect method* } \\
\hline & & $\begin{array}{c}\text { 1-hour duration } \\
\text { of mitosis }\end{array}$ & $\begin{array}{l}30 \text {-minute dura- } \\
\text { tion of mitosis }\end{array}$ \\
\hline Thymus & 4.5 days & 3. 68 days & 1.84 days \\
\hline Mesenteric lymph nodes & 12.8 days & 5.26 days & 2.63 days $i$ \\
\hline Other lymph nodes & 15. 0 days & 5.56 days & 2.87 days \\
\hline
\end{tabular}

* Assumed that the mitotic time is of 1 -hour and of 30 -minute duration.

On the basis of the assumptions noted above, the turnover time of the lymphocytes in the thymolymphatic organs was calculated, using the normal values of the mitotic index listed in Table 1. The results are given in Table 6 , together with the figures estimated directly by using colchicine method. It is seen from the table that the figures obtained by the indirect calculations generally give much lower values of the turnover time than those estimated directly by the colchicine method. Because of the toxic action of the drug mentioned above, the figure estimated by the colchicine method would probably be in the direction of an overestimate.* On the contrary, the calculation based on mitotic time of 30 -minute duration would perhaps result in an underestimate, since the mitotic time of dividing

* In this connection, the effect of adrenalectomy on the mitotic activity in the thymolymphatic tissues, that is, a considerable reduction in the values of the mitotic indix observed from 4 to 8 hours after operation, must also be taken into account. 
cells in the thymolymphatic organs appears to be longer than 30 minutes.

\section{Summary}

1. Using male albino rats of a subline of the $\mathrm{W}$ is t a $\mathrm{r}$ strain weighing around $200 \mathrm{~g}$, a series of quantitative measurements on the mitotic activity in the thymolymphatic organs have been made, with the aim to make possible a calculation of the total number of lymphocytes produced by mitosis per day in the thymolymphatic system. Mitotic counts were performed after suspensions of cell nuclei had been prepared from the thymolymphatic organs according to the technique described in the preceding paper (I t o, 1959).

2. Normal values of the mitotic index were found to be $1.13 \pm$ $0.06 \%$ in the thymus, $0.79 \pm 0.06 \%$ in the mesenteric lymph nodes, and $0.75 \pm 0.06 \%$ in the other lymph nodes.

3. The total percentage of mitoses per day in different organs of the thymolymphatic system was estimated to be $22.23 \pm 0.77 \%$ in the thymus, $7.85 \pm 0.37 \%$ in the mesenteric lymph nodes, and $6.65 \pm 0.26 \%$ in the other lymph nodes. These figures were obtained after repeating the same experiment with colchicine over 4 successive 6 -hour periods so as to cover a total of 24 hours.

4. Using the data of $\mathrm{M}$ ond en (1959a) on the total number of lymphocytes contained in the thymolymphatic organs, the average number of excess mitoses of lymphocytes in the whole thymolyphatic organs was calculated to be $432 \times 10^{6}$. This is 3.3 times as great as the number of total lymphocytes present in the circulating blood.

5. By a direct calculation from the figures obtained for the daily mitotic rate, the turnover time of the lymphocytes in each organ of the thymolymphatic system was estimated to be 4.5 days in the thymus, 12.8 days in the mesenteric lymph nodes, and 15.0 days in the other lymph nodes.

6. Besides, an indirect calculation of the turnover time was made from $\mathrm{H}$ of $\mathrm{fm}$ an's formula, assuming that the mitotic time of dividing cells in the thymolymphatic tissue is of 1-hour and of 30-minute duration.

\section{References}

Andreasen, E. and Christensen, S. 1949. The rate of mitotic activity in the lymphoid organs of the rat. Anat. Rec., 103: 401-412. 
Andreasen, E. and $\mathrm{Ottesen,J.} \mathrm{1945.} \mathrm{Studies} \mathrm{on} \mathrm{the} \mathrm{lymphocyte} \mathrm{production.}$ Investigation of the nucleic acid turnover in the lymphoid organs. Acta physiol. scandinav., $10: 258-270$.

Bertalanffy, F.D. and Leblond, C.P. 1953. The continuous renewal of the two types of alveolar cells in the lung of the rat. Anat. Rec., 115: 515-542.

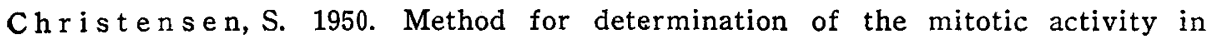
haemopoietic tissues. Acta. anat., 10:233-237.

Hof f ma n, J.G. 1947. Wright's hypothesis: Its relation to volume growth of tissue cells and mitotic index. Science, 106 : 343-344.

- 1953. The Size and Growth of Tissue Cells. Springfield, Illinois: Charles C. Thomas.

It o, H. 1959. Quantitative studies on the rate of call production in the thymolymphatic organs. I. A simple method for determination of the mitotic index in suspension of cell nuclei. Okajimas Fol. anat. jap., 33: 275-284.

$\mathrm{J}$ a $\mathrm{f} f \mathrm{e}, \mathrm{J} . J$. 1954. Diurnal mitotic periodicity in regenerating rat liver. Anat. Rec., 120 : 935-954.

Kindred, J.E. 1942. A quantitative study of the hemopoietic organs of young adult albino rats. Am. J. Anat., $67: 99-149$.

-1955. Quantitative studies on lymphoid tissues. Ann. New York Acad. Sci., 59, Art 5 : 746-754.

Leblond, C.P. and Walker, B.E. 1956. Renewal of cell populations. Physiol. Rev., 36 : 255-276.

Lushaugh, C.C. 1956. Morphologic methods of determining cellular doubling times: A review. J. Histochem. \& Cytochem., 4: 499-507.

Monden, Y. 1955. Total number of lymphocytes contained in the thymolymphatic system of rats as estimated by means of DNA determination. Acta haemat. jap., 18: 617-624. (In Japanese with English summary.)

- 1959a. Quantitative evaluation of total cellular number and cellnlar density in the thymolymphatic organs of young adult albino rats by means of DNA determination. Okajimas Fol. anat. jap., 32: 193-206.

- 1959b. A quantitative study of cell populations in the circulating blood of young adult albino rats. Okajimas Fol. anat. jap., 32 : 207-213.

M ü $\mathrm{h}$ e m a n n, H.R., Marthaler, Th. M. and R a te i t s chak, K. H. 1956. Mitosenperiodik in der Nebennierenrinde, Schildrüse, im Duodenal- und Mündhöhlenepithel der Ratte. Acta anat., $28: 331-341$.

O sogoe, B. and Awaya, K. 1958. Turnover of cell populations in blood and blood-forming tissue. Acta haemat. jap., 21 (Suppl.) : 408-418.

Os ogoe, B., Monden, Y. and Ito, H. 1957. Étude quantitative de la production cellulaire par le systéme thymo-lymphatique du rat. Sang., 28 : 729-737.

Price, D. (ed.) 1958. Dynamics of Proliferating Tissues. (The Developmental Biology Conference Series, 1956.) Chicago: Univ. of Chicago Press. 